\title{
Assessment of Wind Pattern Accuracy from the QuikSCAT Satellite and the WRF Model along the Galician Coast (Northwest Iberian Peninsula)
}

\author{
M. C. SousA \\ CESAM, Departamento de Física, Universidade de Aveiro, Aveiro, Portugal \\ I. AlvareZ \\ Environmental Physics Laboratory, Universidade de Vigo, Facultade de Ciencias, Ourense, Spain, and CESAM, \\ Departamento de Física, Universidade de Aveiro, Aveiro, Portugal \\ N. VAZ \\ CESAM, Departamento de Física, Universidade de Aveiro, Aveiro, Portugal \\ M. GOMEZ-GESTEIRA \\ Environmental Physics Laboratory, Universidade de Vigo, Facultade de Ciencias, Ourense, Spain \\ J. M. DIAS \\ CESAM, Departamento de Física, Universidade de Aveiro, Aveiro, Portugal
}

(Manuscript received 15 December 2011, in final form 20 August 2012)

\begin{abstract}
Surface wind along the Galician coast is a key factor allowing the analysis of important oceanographic features that are related to the great primary production in this area, as upwelling events. A comparative analysis between surface winds obtained from the Quick Scatterometer (QuikSCAT), the Weather Research and Forecasting (WRF) Model, and in situ observations from buoys along the Galician coast is carried out from November 2008 to October 2009. This comparison evaluates the accuracy of satellite and modeled data. The results show that the wind speeds derived from QuikSCAT and the WRF Model are similar along the coast, with errors ranging from 1.5 to $2 \mathrm{~m} \mathrm{~s}^{-1}$. However, QuikSCAT tends to overestimate wind speeds when compared to the buoys measurements. Regarding the wind direction, the RMSE values are about $35^{\circ}$ for the stations under analysis. The bias presents a similar pattern between satellite and modeled data, with positive values at the western coast and negative values at the middle and northern coasts, the satellite data always being lower in absolute value than the modeled data. A spatial comparison between QuikSCAT and WRF data is also performed over the whole Galician coast to evaluate the differences between the two datasets. This comparison shows that the modeled wind speed tends to be lower than satellite winds over the entire domain, with the highest RMSE and bias values found for the wind speed and direction observed near the shoreline.
\end{abstract}

\section{Introduction}

Surface winds over open sea and near coastlines have a great impact on many economic activities, including

\footnotetext{
Corresponding author address: J. M. Dias, CESAM, Departamento de Física, Universidade de Aveiro, Campus de Santiago, 3810-193 Aveiro, Portugal.

E-mail: joao.dias@ua.pt
}

ship routing, coastal management, and fisheries. For example, in the absence of strong ambient flows, the spreading of plumes and local oceanographic features of ecological relevance, as upwelling regime, are highly dependent on wind stress. Thus, in coastal areas, the study of the wind-induced phenomena becomes extremely important. In addition to their meteorological interest and importance, surface winds play a key role in numerical studies, being a major forcing mechanism of 
the circulation of coastal ocean models. This implies that errors in the determination of the surface wind will change the model forcing and consequently will modify the output of the ocean circulation models.

Therefore, for various offshore applications it is fundamental to have accurate wind speed and direction, and consequently appropriate measuring tools for their observation or prediction are essential. The available data for observational studies over the ocean regions have typically been provided through in situ measurements using the oceanographic buoys as well as by satellite scatterometry. Additionally, high-resolution atmospheric models are also frequently used to provide useful wind predictions. The data provided from buoys are wind observations at a single point, coastal or offshore. Satellite data and model predictions of the surface wind field refer to extended gridded spatial and temporal scales, containing more information than isolated buoys. It should also be noted that satellite measurements are not available near the coast, limiting its applications in those areas. On the other hand, model predictions can also be less reliable close to the coast due to the discretization regarding the inland topography.

The Galician shoreline can be divided in three regions (Fig. 1): the western coast, stretching from the northern part of Portugal to Cape Finisterre; the middle coast, from Cape Finisterre to Cape Ortegal; and the northern coast, eastward of Cape Ortegal. There are two typical wind regimes over the Galician coast: autumn-winter, dominated by south-southwesterly wind and spring-summer, dominated by north-northeasterly wind. However, the summer patterns may dominate in winter and vice versa (Torres et al. 2003; Gomez-Gesteira et al. 2006; Alvarez et al. 2008). Thus, upwelling favorable northerly winds occur mainly during spring-summer along the Galician coast (Fraga 1981; Bode et al. 2002; Alvarez et al. 2008, 2010) although theses phenomena can be also observed in autumn-winter (Alvarez et al. 2003; deCastro et al. 2006, 2008; Prego et al. 2007; Alvarez et al. 2009).

Several studies have been carried out in terms of wind patterns along the Galician coast (Torres et al. 2003; Alvarez et al. 2005; Gomez-Gesteira et al. 2006; Alvarez et al. 2008; Ospina-Alvarez et al. 2010; Alvarez et al. 2011). According to these studies, the wind field along this coast is far from homogenous due to the particular coastal topography and orientation, which modulates wind direction and intensity. Wind observations at a single point, coastal or offshore, will not necessarily be representative of the wind conditions along the entire coast (Torres et al. 2003). In this way, the analysis of wind regime along this coast constitutes an important task, although the lack of real wind measurements (e.g., buoys and meteorological stations) obtained simultaneously

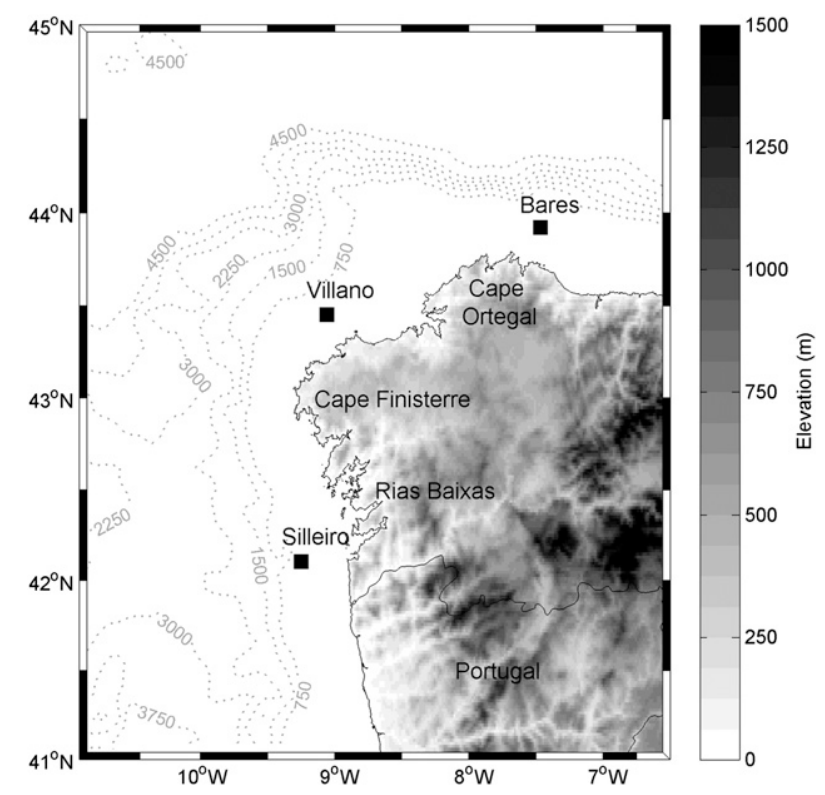

FIG. 1. Bathymetry (m) and subaerial relief $(\mathrm{m})$ of the Galician coast. Black squares correspond to the location of oceanographic buoys.

and over long time periods makes the analysis of the wind patterns difficult near the shoreline. To overcome this difficulty, data provided by satellites as the Quick Scatterometer (QuikSCAT) and atmospheric models, can be used to study the wind regime over the area.

During the last years, several studies have been published with comprehensive statistical analysis of QuikSCAT data compared to buoys and model results all over the oceans; for example, the U.S. western coast (Pickett et al. 2003; Chelton and Freilich 2005), the U.S. northwestern coast (Tang et al. 2004), the Indian Ocean (Satheesan et al. 2007), and the Mediterranean Sea (Accadia et al. 2007; Bentamy et al. 2007; Ruti et al. 2008; Pensieri et al. 2010). The Galician coast has also been analyzed by means of similar studies: Alvarez et al. (2006) carried out a comparison between wind data provided by an atmospheric regional model and by QuikSCAT from 2001 to 2005. This comparison examined the accuracy of wind data to predict a spill extension. Both datasets showed a high correlation, although QuikSCAT presented slightly higher wind intensity (about 15\%). Alvarez et al. (2008) compared wind obtained from QuikSCAT and oceanographic buoys located around the Galician coast from 1999 to 2005. Results showed that the wind buoy's data amplitude was slightly smaller (about 12\%) than the QuikSCAT one. A statistical analysis was also performed by Penabad et al. (2008) to compare wind measurements obtained by QuikSCAT satellite with wind forecasts from two different operational 
numerical models in the northwestern Iberian Peninsula for a 4-yr period (2002-05). This comparison revealed no significant differences between models and satellite data and the error magnitudes were similar for both datasets. Otero and Ruiz-Vilarreal (2008) evaluated the reliability of different meteorological models through the comparison with observed winds around the northwest and north Iberia during autumn 2002 showing significant differences among modeled wind data products.

As it can be derived from previously published work, QuikSCAT is a useful tool to study the wind-induced phenomena in the open ocean and near the coast. However, it is necessary to keep in mind the existence of a small land mask (about $25 \mathrm{~km}$ ) near the shore where data are not available. In fact, it has been observed that QuikSCAT wind data tend to be more accurate offshore than nearshore (Pickett et al. 2003; Tang et al. 2004). This lack of satellite wind measurements near the coast can be overcome using numerical models. Thus, models also constitute an important tool to characterize the wind regime solving certain wind features that the satellite is roughly able to estimate, especially near the shore. Nevertheless, results can also depend on the discretization of the model regarding the complexity of coastal topography. Since wind conditions in the Galicia coast are highly variable due to the change of coastline orientation and the complex topography caused by the presence of estuaries, it is crucial to accurately assess wind events by comparing observations taken at the same time through different methods all along the coast. The works previously described consist in a first approach on the analysis of the satellite and model errors based on correlation comparisons. The goal of this study is to carry out a more detailed and thorough study of these aspects, regarding not only wind speed but also wind direction. Thus, the quality of nearshore data provided by satellite and modeled data is evaluated for future applications.

Therefore, the main aim of this study is a comparison between surface winds obtained from QuikSCAT data, the Weather Research and Forecasting (WRF) Model predictions, and in situ wind measurements along the Galician coast. Following the previous description of this coast based on the shoreline orientation three coastal areas were analyzed: the western, intermediate, and northern coast. This comparison will evaluate the accuracy of satellite and modeled data, assessing their errors relatively to buoy data. A detailed analysis will be carried out considering different limits of wind speed and also considering the four main direction sectors. In addition, a spatial comparison between QuikSCAT and WRF data will be performed for the whole Galician coast, to determine the differences between both datasets.
This comparison will evaluate wind data quality close to the coast, assessing its applicability to study wind-induced coastal phenomena.

\section{Material and methods}

Surface wind fields obtained by the QuikSCAT satellite are available from July 1999 to November 2009 and were retrieved from the Jet Propulsion Laboratory website (ftp://podaac-ftp.jpl.nasa.gov/allData/quikscat/ L3/jpl/v2/hdf/). This dataset consists of global grid values of meridional and zonal components of wind, measured twice a day in an approximately $0.25^{\circ} \times 0.25^{\circ}$ global coverage grid. Data are given in an ascending (0600 LT) and descending (1800 LT) pass and provided with a rain flag. Wind intensity measurements range from 3 to $20 \mathrm{~m} \mathrm{~s}^{-1}$, with an accuracy of $2 \mathrm{~m} \mathrm{~s}^{-1}$ and $20^{\circ}$ in direction (Jet Propulsion Laboratory 2001). The reference height of wind data is $10 \mathrm{~m}$. In addition, it is necessary to note that the wind data close to the coast $(\sim 25 \mathrm{~km})$ are not available due to the existence of a small land mask. Therefore, QuikSCAT wind measurements tend to be more accurate offshore than nearshore and the accuracy values may differ from the ones mentioned above (Pickett et al. 2003; Tang et al. 2004). From the analysis carried out over several ocean regions (Portabella and Stoffelen 2001; Stiles and Yeuh 2002; Milliff et al. 2004; Chelton and Freilich 2005), it was found that the accuracy of QuikSCAT wind data is very low when the observations are taken under rainy conditions. This is because scattering from rain drops is higher than the scattering produced by wind action over the sea surface (Portabella and Stoffelen 2001). Thus, QuikSCAT data marked with a rain flag were discarded to carry out the study. To perform a spatial analysis of the entire area under study, some gaps detected in daily data were objectively interpolated between the four surrounding grid points. This interpolation affects less than $10 \%$ of the total data.

Predicted wind data around the Galician coast were also provided by the Regional Forecast Agency Meteogalicia (http://www.meteogalicia.es) through the WRF Model (http://www.wrf-model.org). The Advanced Research (ARW) core of WRF is ran operationally twice a day, producing numerical weather predictions up to $72 \mathrm{~h}$ over Galicia. Three two-way nested domains are configured: the first one with $36-\mathrm{km}$ resolution covering the southwest of Europe, the second one with 12-km resolution covering the Iberian Peninsula, and the third with 4-km resolution over Galicia. In this study, results from the last domain are used. Table 1 summarizes the combinations of microphysics and cumulus parameterizations used with other physics options provided by Meteogalicia. 
TABLE 1. Summary of the WRF parameterizations.

\begin{tabular}{ll}
\hline & WRF physics options (three domains) \\
\hline PBL scheme & Yonsei University (YSU) \\
Cumulus & Grell \\
Microphysics & Thompson \\
Longwave radiation & Rapid Radiative Transfer Model scheme \\
Shortwave radiation & Dudhia scheme \\
Ground temperature & Five-layer soil model \\
\hline
\end{tabular}

The wind generated by the model at $10 \mathrm{~m}$ over the sea surface (outputted hourly) is from the PBL scheme (see Table 1). Only the measurements corresponding to 0600 and 1800 LT were used for comparison purposes. A more detailed description of the model can be found in Skamarock et al. (2008).

Wind data measured at three oceanographic buoys moored near the Galician shelf break were also considered. These buoys, supported by the Spanish Agency Puertos del Estado, are situated at Silleiro $\left(42^{\circ} 7.2^{\prime} \mathrm{N}, 9^{\circ} 24^{\prime} \mathrm{W}\right.$ at $44 \mathrm{~km}$ from land), Villano $\left(43^{\circ} 29.4^{\prime} \mathrm{N}, 9^{\circ} 12.6^{\prime} \mathrm{W}\right.$ at $30 \mathrm{~km}$ from land), and Bares $\left(44^{\circ} 3.6^{\prime} \mathrm{N}, 7^{\circ} 37.2^{\prime} \mathrm{W}\right.$ at $38 \mathrm{~km}$ from land; Fig. 1, squares). They measure wind vectors only over 10 min every hour at the 3-m level. Then an average is calculated and hourly wind vectors are stored.

All datasets cover the period from November 2008 to October 2009 (the last year of available QuikSCAT data), except the wind data provided by the buoys, which do not contain continuous data for this period (Table 2).

To compare the different datasets, wind speed values provided by the oceanographic buoys were adjusted to a 10-m height, assuming neutral stability and a logarithmic wind profile (Large and Pond 1981; Johnson 1999). The method of a logarithmically varying wind vertical profile (Ruti et al. 2008) was used instead of other methods considering algorithms based on neutral stability correction (Liu et al. 1979; Liu and Tang 1996) due to the lack of atmospheric pressure, relative humidity, and air and sea surface temperature data. To adjust the time in wind vectors from all databases, the measurements of buoy winds corresponding to 0600 and 1800 LT were used. The spatial collocation between databases was carried out with the QuikSCAT/WRF grid point closest to the location of each buoy.

After discarding rain flag values from QuikSCAT and considering the lack of observations in the different databases, the analysis was performed to $45 \%$ ( 326 valid samples), $40 \%$ (290 valid samples), and 53\% (388 valid samples) of the total data at the Silleiro, Villano, and Bares stations, respectively.

To evaluate the adjustment between the different wind databases, a statistical analysis was carried out examining the wind speed and wind direction by means of the
TABLE 2. Available data at the three ocean buoys during the period under study, covering the period November 2008-October 2009.

\begin{tabular}{lcc}
\hline \hline Station & Start & End \\
\hline Silleiro & 5 Dec 2008 & 6 Mar 2009 \\
Villano & 31 Mar 2009 & 16 Jul 2009 \\
& 1 Nov 2008 & 29 Jan 2009 \\
Bares & 30 Mar 2009 & 24 Jul 2009 \\
& 31 Jul 2009 & 9 Aug 2009 \\
& 1 Nov 2008 & 23 Jan 2009 \\
& 31 Mar 2009 & 17 Jul 2009 \\
& 31 Jul 2009 & 31 Oct 2009 \\
\hline
\end{tabular}

correlation coefficient, $r_{D, B}=\operatorname{cov}(D, B) / \sigma_{D} \sigma_{B}$, the rootmean-square error, RMSE $=\left[(1 / n) \sum_{i=1}^{n}\left(D_{i}-B_{i}\right)^{2}\right]^{1 / 2}$, and the bias $=(1 / n) \sum_{i=1}^{n}\left(D_{i}-B_{i}\right)$, where $D$ corresponds to wind data from QuikSCAT/WRF and $B$ corresponds to buoys. A weighted mean was also calculated for the RMSE and bias following $\bar{x}=\sum_{i=1}^{n} x_{i} w_{i} / \sum_{i=1}^{n} w_{i}$, where $w$ corresponds to the data weight (number of data).

The differences between QuikSCAT-buoy and WRFbuoy wind direction were also calculated to better evaluate the wind vector differences. To reduce the discontinuity between $0^{\circ}$ and $360^{\circ}$, the QuikSCAT and WRF wind direction was modified using the methodology proposed by Pensieri et al. (2010), which consists of $\theta_{D}=\theta_{D}-360^{\circ}$ when $\theta_{D}-\theta_{B}>180^{\circ}$ and $\theta_{D}=\theta_{D}+360^{\circ}$ when $\theta_{D}-\theta_{B}<-180^{\circ}$.

\section{Results and discussion}

\section{a. Comparison with in situ observations}

\section{1) WIND SPEED ANALYSIS}

To characterize the wind regime over the area under study, the percentage of events obtained for each range of wind speed according to the Beaufort wind force scale in each buoy was summarized in Table 3. The wind speed statistics reveal that the probability of light winds (lower than $3.3 \mathrm{~m} \mathrm{~s}^{-1}$ ) ranges from $9 \%-18 \%$. Gentle, moderate, and fresh breezes represent the prevailing wind regime of this region showing similar percentage values that correspond to a total amount of $63 \%-69 \%$. Finally, the probability of strong winds $\left(>13.8 \mathrm{~m} \mathrm{~s}^{-1}\right)$ is very low, ranging from $3 \%-8 \%$.

Wind roses were also represented to analyze the distribution of wind vectors at the three stations measured by the oceanographic buoys (Fig. 2). Bars indicate the direction from which the wind blows. At the Silleiro station, the wind blows predominantly from the north and northwest directions (alongshore). South winds are also observed although with a lower frequency. At the 
TABLE 3. Percentage of events obtained for each range of wind speed according to the Beaufort scale at the three ocean buoys from November 2008 to October 2009.

\begin{tabular}{clccc}
\hline $\begin{array}{c}\text { Limits of wind speed } \\
\left(\mathrm{m} \mathrm{s}^{-1}\right)\end{array}$ & $\begin{array}{c}\text { Wind descriptive } \\
\text { terms }\end{array}$ & $\begin{array}{c}\text { Silleiro } \\
(\%)\end{array}$ & $\begin{array}{r}\text { Villano } \\
(\%)\end{array}$ & $\begin{array}{c}\text { Bares } \\
(\%)\end{array}$ \\
\hline$<1.5$ & Calm & 6 & 2 & 3 \\
$1.6-3.3$ & Light breeze & 12 & 7 & 9 \\
$3.4-5.4$ & Gentle breeze & 21 & 18 & 19 \\
$5.5-7.9$ & Moderate breeze & 20 & 26 & 23 \\
$8.0-10.7$ & Fresh breeze & 22 & 22 & 27 \\
$10.8-13.8$ & Strong breeze & 16 & 17 & 15 \\
$>13.9$ & Near gale & 3 & 8 & 4 \\
\hline
\end{tabular}

Villano station, the behavior is slightly different showing northeast and southwest winds with similar frequencies. At the Bares station was found prevalence of intense easterly wind, whose amplitude tends to surpass $8 \mathrm{~m} \mathrm{~s}^{-1}$. The second most prevailing winds are westerly showing lower intensity than observed for easterly winds. These results show that coastal winds tend to be aligned with coastal orientation (Gomez-Gesteira et al. 2006; Alvarez et al. 2008, 2011). In addition, these wind patterns indicate upwelling favorable conditions during most of the period under study all along the Galician coast. This situation is especially remarkable at the western coast (Silleiro), which is characterized by the prevalence of intense north winds (upwelling favorable), indicating that these conditions can also occur during autumnwinter (Alvarez et al. 2003; deCastro et al. 2006; Prego et al. 2007; deCastro et al. 2008; Varela et al. 2008, 2010; Alvarez et al. 2009). The occurrence of upwelling events during these seasons can have implications on biogeochemical and phytoplankton patterns (Borja et al. 1996; Santos et al. 2004; Prego et al. 2007). These circumstances indicate that the accurate wind regime characterization during periods as the one analyzed in the present study is fundamental to clarify the occurrence of these phenomena and, consequently, to determine their possible impact on coastal ecosystems.

To compare the three databases, wind speed and direction were analyzed separately. Wind speed data from QuikSCAT, WRF, and buoys were fitted to a Weibull distribution in order to characterize the variability among the different datasets and to calculate the probability of finding a particular wind speed at each coastal station (Fig. 3). Weibull distribution gives an approximate but generally good fit to the observed wind speed distribution (Otero et al. 2008). The selection of this distribution is often attributed to its flexibility, which assures a good fit to the observed data. Moderate winds are very common all along the coast, although some differences can be observed depending on the coastal area. At the western and middle coast a similar pattern can be observed
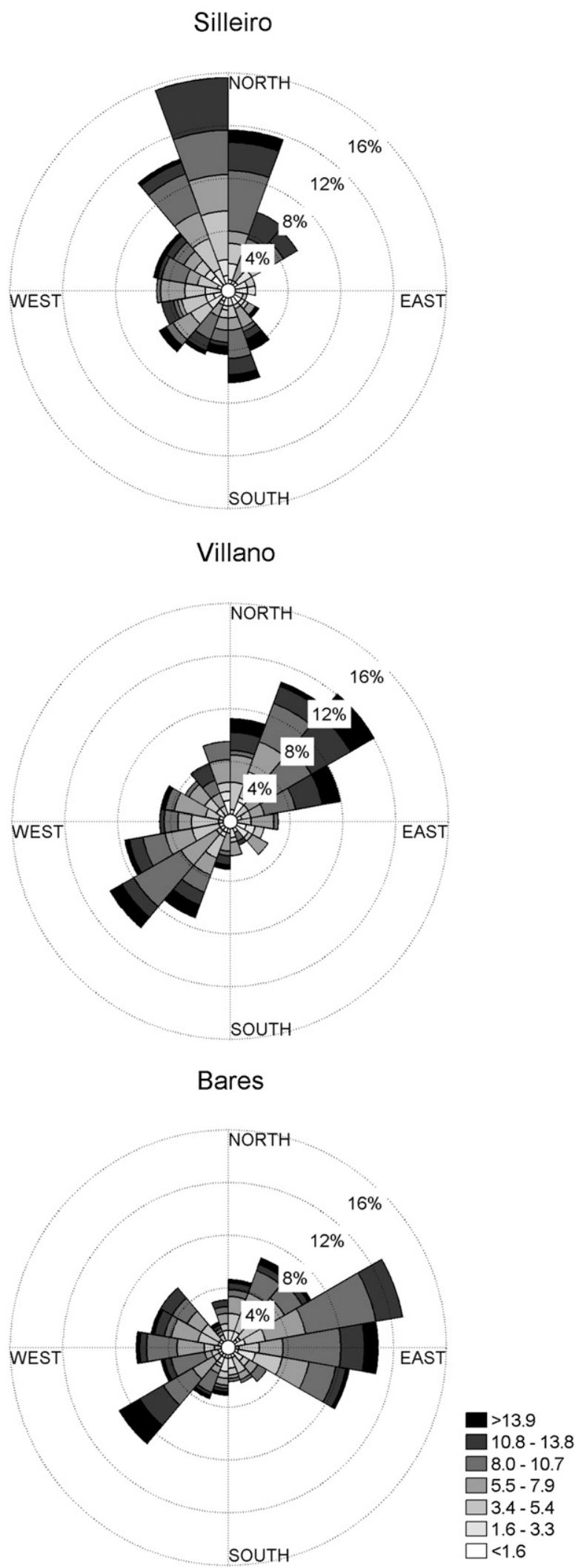

FIG. 2. Wind rose diagrams $\left(\mathrm{m} \mathrm{s}^{-1}\right)$ calculated at the three oceanographic buoys over the period November 2008 to October 2009. 


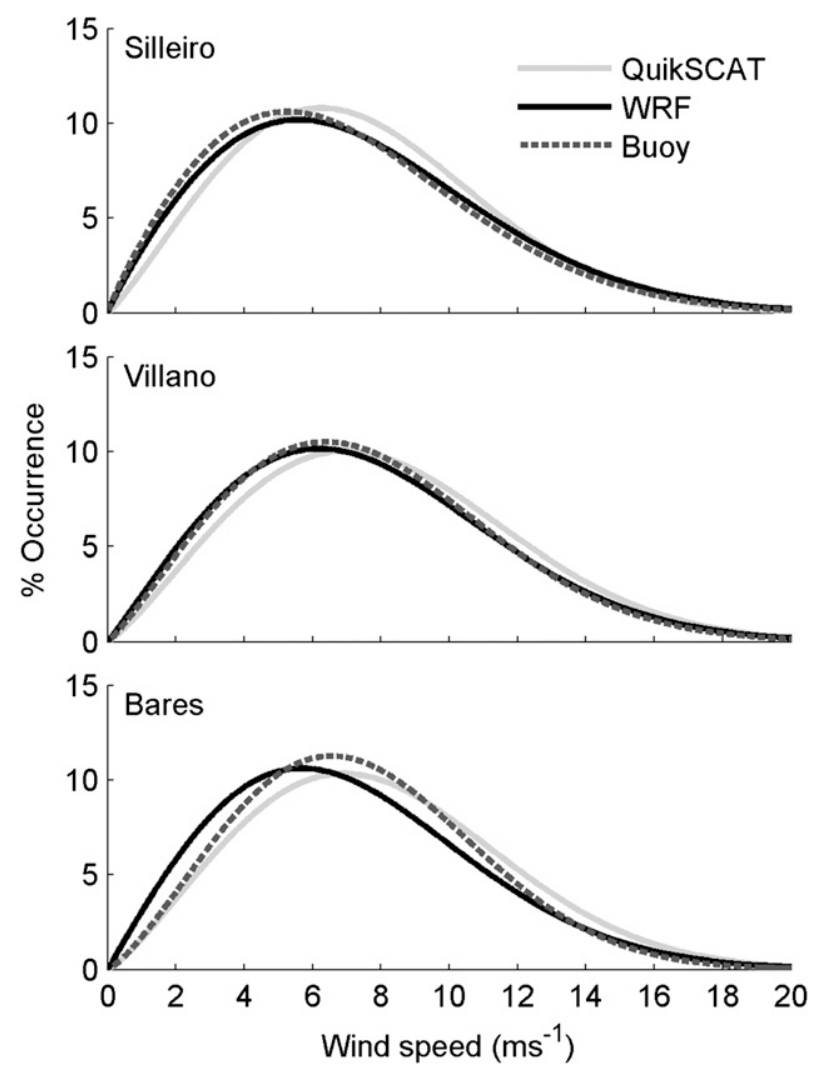

FIG. 3. Wind speed occurrence at the three stations fitted to a Weibull distribution [QuikSCAT (gray), WRF (black), and buoy (dashed lack)] over the period November 2008 to October 2009.

between WRF and in situ wind observations showing almost the same behavior. QuikSCAT tends to underestimate (overestimate) the occurrence of winds lower (higher) than $5-6 \mathrm{~m} \mathrm{~s}^{-1}$. At the northern coast the distributions of QuikSCAT and WRF data are different from the buoy data, indicating a lower accuracy for both databases at this coastal area.

Table 4 shows the Weibull shape parameter $\kappa$, which refers to the width of the distribution, and the scale parameter $\lambda$, which is related to the mean wind speed. The most commonly occurring wind speed $W_{m}$ was also considered. The shape parameter presents values of 2 at the three stations independently of the database. The maximum value of the scale factor is obtained for QuikSCAT data at the three stations (between 8.4-9.1 $\mathrm{m} \mathrm{s}^{-1}$ ). In addition, the scale parameter corresponding to the model and buoys show a similar magnitude at the three stations indicating that the WRF Model predictions presents better results than the satellite measurements. The most common wind speed ranges from about 5 to $7 \mathrm{~m} \mathrm{~s}^{-1}$ among the different databases and stations showing that moderate winds are very common. The highest value of $W_{m}$ is also observed
TABLE 4. Weibull shape parameter $\kappa$, scale parameter $\lambda$, and the most commonly occurring wind speed $W_{m}$ corresponding to the Weibull distributions shown in Fig. 3.

\begin{tabular}{llccc}
\hline \hline Station & & $\kappa$ & $\lambda\left(\mathrm{m} \mathrm{s}^{-1}\right)$ & $W_{m}\left(\mathrm{~m} \mathrm{~s}^{-1}\right)$ \\
\hline Silleiro & Buoy & 1.9 & 7.9 & 5.4 \\
& WRF & 1.9 & 8.2 & 5.6 \\
\multirow{4}{*}{ Villano } & QuikSCAT & 2.1 & 8.4 & 6.2 \\
& Buoy & 2.1 & 8.6 & 6.4 \\
& WRF & 2.0 & 8.6 & 6.2 \\
\multirow{5}{*}{ Bares } & QuikSCAT & 2.2 & 9.1 & 6.9 \\
& Buoy & 2.3 & 8.4 & 6.5 \\
& WRF & 2.0 & 8.1 & 5.7 \\
& QuikSCAT & 2.2 & 9.0 & 6.9 \\
\hline
\end{tabular}

for QuikSCAT data at the three stations (between 6.2 and $6.9 \mathrm{~m} \mathrm{~s}^{-1}$ ). At the western and middle coast, model predictions and buoys data show a similar value. Nevertheless, at the northern coast, QuikSCAT data present a value of $W_{m}$ closer to the buoy measurements showing a higher accuracy of the satellite to measure these winds.

A more detailed analysis can be carried out considering different limits of wind speed. According to the results shown in Table 3, three different intervals are considered. The first one includes calm and light breezes $\left(0-3.3 \mathrm{~m} \mathrm{~s}^{-1}\right)$, the second corresponds to values between gentle and fresh breezes $\left(3.4-10.7 \mathrm{~m} \mathrm{~s}^{-1}\right)$, and the last one considers values higher than strong breezes $\left(>10.8 \mathrm{~m} \mathrm{~s}^{-1}\right)$. Table 5 shows the RMSE and bias calculated for these intervals using the QuikSCAT/WRF and buoy data. The different limits of wind speed are classified according to the values measured by the buoy. The bias is calculated as the difference between QuikSCAT/WRF values and buoy values. Thus, a positive bias in wind speed means that QuikSCAT/WRF tends to overestimate winds. The analysis by speed intervals shows similar RMSE results for QuikSCAT and WRF at the three stations. Bias distribution is less consistent. RMSE values tend to be higher at low winds $\left(<3.3 \mathrm{~m} \mathrm{~s}^{-1}\right)$ for satellite and modeled data at the three stations agreeing with the highest values of bias. Moderate winds show the lowest errors also at the three stations both for QuikSCAT and WRF. Note that these winds are the most commonly observed along the coast (Fig. 3) and therefore, the highest number of samples is obtained within this interval. The statistical analysis was also carried out over the whole range speed (last row) and a weighted mean was calculated at the three stations, in terms of the number of samples existent in each bin. Thus, some data points contribute more than others to the final average. When comparing wind speed results for the three locations, the RMSE values obtained for the satellite (about $1.5 \mathrm{~m} \mathrm{~s}^{-1}$ ) are always lower than 
TABLE 5. Statistics of the comparison between QuikSCAT, WRF, and buoy wind speed at the three stations. Last row shows a weighted mean calculated over the whole range of wind speed.

\begin{tabular}{|c|c|c|c|c|c|c|c|c|c|c|c|c|}
\hline \multirow{2}{*}{$\begin{array}{l}\text { Wind speed } \\
\text { range }\left(\mathrm{m} \mathrm{s}^{-1}\right)\end{array}$} & \multicolumn{4}{|c|}{ Silleiro } & \multicolumn{4}{|c|}{ Villano } & \multicolumn{4}{|c|}{ Bares } \\
\hline & RMSE-Q & RMSE-W & Bias-Q & Bias-W & RMSE-Q & RMSE-W & Bias-Q & Bias-W & RMSE-Q & RMSE-W & Bias-Q & Bias-W \\
\hline$<3.3$ & 1.6 & 2.2 & 1.2 & 1.3 & 2.3 & 2.5 & 1.6 & 1.3 & 1.5 & 1.8 & 0.9 & 0.6 \\
\hline $3.4-10.7$ & 1.3 & 1.9 & 0.2 & 0.1 & 1.3 & 1.8 & 0.3 & -0.1 & 1.4 & 1.9 & 0.3 & -0.5 \\
\hline$>10.8$ & 1.6 & 2.0 & 0.4 & 0.2 & 2.0 & 2.2 & 0.4 & -0.2 & 1.6 & 1.9 & 0.9 & 0.1 \\
\hline Mean & 1.4 & 2.0 & 0.4 & 0.3 & 1.5 & 2.0 & 0.4 & 0.1 & 1.5 & 1.9 & 0.5 & -0.3 \\
\hline
\end{tabular}

those for the model (about $2 \mathrm{~m} \mathrm{~s}^{-1}$ ). Bias shows the opposite behavior with the lowest absolute values found for the model. In addition, bias is always positive for QuikSCAT (about $0.5 \mathrm{~m} \mathrm{~s}^{-1}$ ), indicating that the satellite overestimates wind intensity at the three stations. For the model there is a clear pattern showing a positive bias value at the western and middle coast and negative one at the northern coast. Thus, at the northern coast, modeled data tend to be lower than in situ observations.

According to the previous results obtained from the Weibull analysis (Fig. 3; Table 4), macroscopically at the western and middle coasts, modeled data tend to present better results than the satellite data, showing wind patterns more similar to those determined from buoys measurements. Nevertheless, from the statistical analysis (Table 5) the RMSE values obtained for the satellite data are lower than the corresponding modeled data, while the bias distribution shows the lowest absolute values for the model.

\section{2) WIND DIRECTION ANALYSIS}

The wind direction variability was analyzed considering the differences between QuikSCAT/WRF and buoy data. Figure 4 shows the dependence of wind direction difference between WRF/buoy (QuikSCAT/ buoy) data on the buoy wind speed at the left column (right column) for the three stations.

A common pattern can be observed for WRF and QuikSCAT with most of the points distributed between $-45^{\circ}$ and $45^{\circ}$. The highest variations are observed for low wind speeds $\left(<3 \mathrm{~m} \mathrm{~s}^{-1}\right)$. In fact, the standard deviations (bars) increase at low wind speeds for the three stations, as consequence of the complexity to define the direction for these events. For low wind speeds, it is more difficult to measure the wind direction. Winds over $15 \mathrm{~m} \mathrm{~s}^{-1}$ were not included in the calculations of the mean (black points) and standard deviation values (bars) because of the low number of samples, since their inclusion could result in a greater margin of error. In addition, high wind speeds are usually associated with bad weather conditions, which can cause buoys oscillations in the higher waves as well as surface layer distortion (Large et al. 1995; Ebuchi et al. 2002) and therefore, buoys measurements become less reliable.

To better characterize the wind direction variability, a detailed analysis was carried out considering the four main direction sectors calculating the RMSE and bias for wind direction at the three stations for QuikSCAT and WRF data (Table 6). As in Table 5, direction sectors are classified according to the values measured by the buoy. The bias is calculated as the difference between QuikSCAT/WRF values and buoy data. Thus, a positive bias in wind direction means that QuikSCAT/WRF tends to rotate winds clockwise. Comparing the wind direction results analyzed by sectors at the three stations, the RMSE is lower for the most frequent sectors (Fig. 2), both for QuikSCAT and WRF. Thus, at the western coast the lowest RMSE values are obtained for southern winds. At the middle coast, the lowest RMSE values correspond to the western direction and at the northern coast to the east and west directions. It is also important to note the higher RMSE obtained for the model at the western coast for west winds $\left(65.5^{\circ}\right)$ and at the northern coast for north winds $\left(65.9^{\circ}\right)$. According to Fig. 2, these winds are uncommon and the high RMSE can be due to the low number of samples. Nevertheless, the RMSE values obtained for QuikSCAT at the same sectors have considerable lower values that could indicate lower model accuracy when in situ measured winds come from land due to an insufficient model resolution regarding the complexity of coastal topography. For bias distribution there is not a clear pattern for QuikSCAT and WRF and values are dependent on the considered sector and station. Weighted means were also used to analyze the overall patterns (lower row). The RMSE values obtained for the satellite and the model are similar at the three stations (around $35^{\circ}$ ). For both databases a positive bias is obtained at the western coast and a negative bias at the intermediate and northern coast. In terms of bias absolute value, the modeled data present lower values at the three stations. Note that they can be dependent on the positive/negative distribution of bias values analyzed by sectors. Thus, at the western 

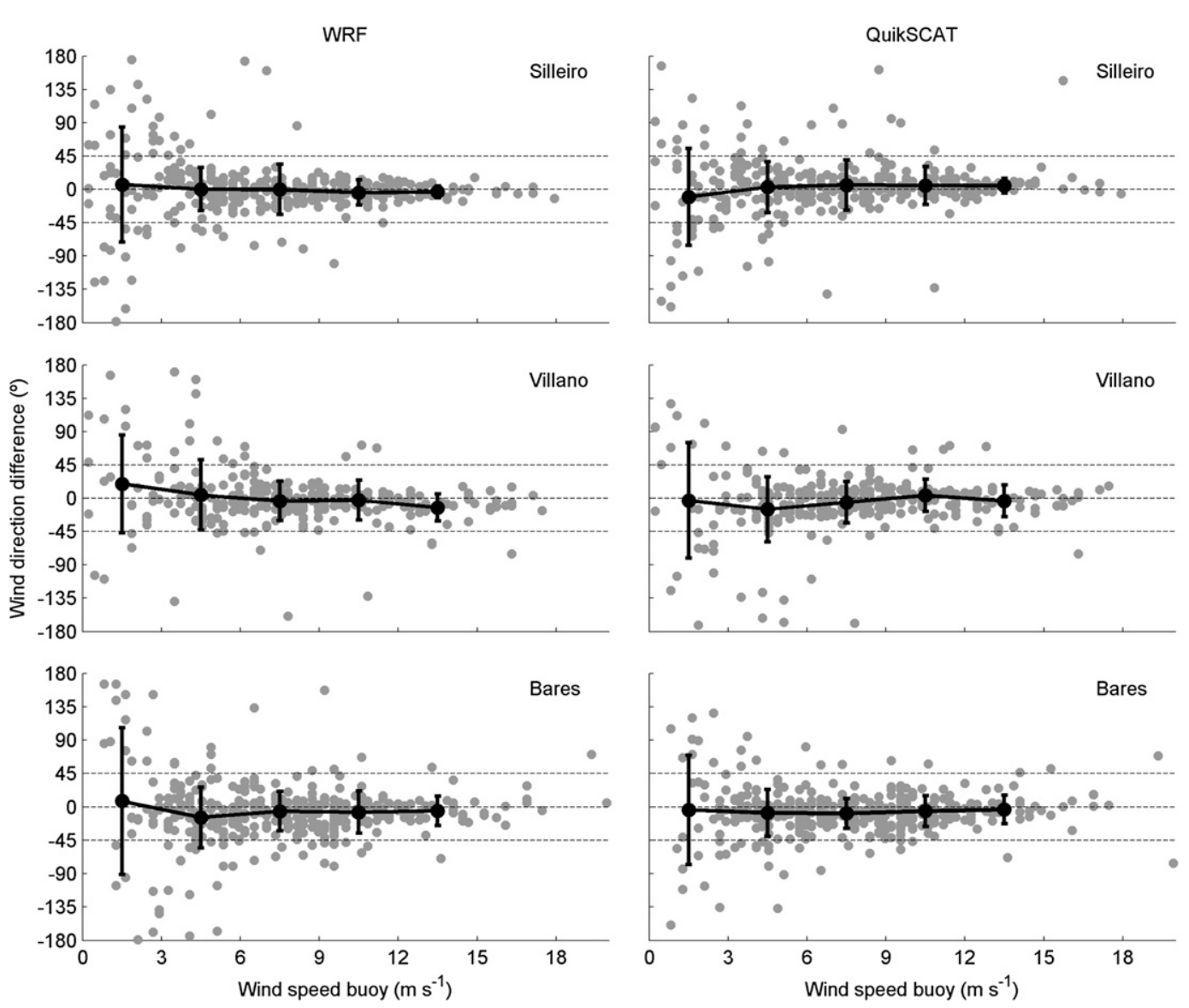

FIG. 4. Dependence of wind direction differences (WRF/buoy and QuikSCAT/buoy) on the buoy wind speed at the three stations (gray points) calculated over the period November 2008 to October 2009. Black points represent the average of the differences based on $3 \mathrm{~m} \mathrm{~s}^{-1}$ bins and bars represent the standard deviation.

coast QuikSCAT tends to present positive bias values, while at the middle and northern coasts bias values tend to be negative. The bias distribution corresponding to the model is less consistent.

\section{b. Spatial analysis}

With respect to the previous results, it was found that the WRF Model and QuikSCAT data reproduce with reasonable accuracy the wind patterns measured by the buoys. In this section, the analysis of both datasets at each grid point around the Galician coast is also evaluated for the full period under study by means of an annual average. The annual mean wind pattern is calculated by averaging daily values provided by QuikSCAT and WRF at each grid point (Figs. 5a,b). For the spatial comparison, model data were interpolated on a grid of $0.25^{\circ} \times 0.25^{\circ}$ using a cubic interpolation. Both datasets reproduce approximately the same pattern in wind direction with some differences in wind speed. The wind speed increases from north to south for both databases showing higher values for satellite data over the entire domain. QuikSCAT minus WRF values were used to evaluate and quantify the differences in wind speed, through the computation of RMSE (Fig. 5c) and bias (Fig. 5d). The maximum RMSE values (about $2.2 \mathrm{~m} \mathrm{~s}^{-1}$ ) are observed around Cape Finisterre mainly closer to the coastline. Bias distribution shows positive values for the entire domain indicating that QuikSCAT tends to overestimate wind speed. The highest values of bias (about $0.7 \mathrm{~m} \mathrm{~s}^{-1}$ ) are also observed north and south of Cape Finisterre near the shoreline. On the one hand, these results could be explained by the land mask for QuikSCAT nearshore data. In fact, previous studies have shown that due to this mask, satellite-measured winds tend to be more accurate offshore than nearshore (Pickett et al. 2003; Tang et al. 2004). On the other hand, it is necessary to consider the possibility of an insufficient model resolution regarding the complexity of the Galician coastal topography, which could influence the model results near the shoreline. Wind direction differences were also analyzed through the RMSE (Fig. 5e) and bias (Fig. 5f). The highest values of RMSE (about 
TABLE 6. Statistics of the comparison between QuikSCAT, WRF, and buoy wind direction at the three stations. The last row shows a weighted mean calculated over the whole direction sectors.

\begin{tabular}{|c|c|c|c|c|c|c|c|c|c|c|c|c|}
\hline \multirow{2}{*}{$\begin{array}{l}\text { Wind direction } \\
\text { sectors }\end{array}$} & \multicolumn{4}{|c|}{ Silleiro } & \multicolumn{4}{|c|}{ Villano } & \multicolumn{4}{|c|}{ Bares } \\
\hline & RMSE-Q & RMSE-W & Bias-Q & Bias-W & RMSE-Q & RMSE-W & Bias-Q & Bias-W & RMSE-Q & RMSE-W & Bias-Q & Bias-W \\
\hline $\mathrm{N}$ & 55.7 & 46.3 & 15.7 & 7.4 & 39.9 & 39.4 & 8.6 & 8.0 & 49.9 & 65.9 & 4.7 & 5.4 \\
\hline $\mathrm{E}$ & 41.3 & 33.0 & 4.4 & -4.9 & 45.3 & 37.2 & -12.2 & -5.3 & 26.3 & 30.7 & -5.4 & -2.0 \\
\hline S & 25.6 & 32.3 & 1.4 & -4.0 & 38.3 & 42.9 & -10.7 & -5.4 & 37.2 & 51.9 & -11.5 & -19.8 \\
\hline W & 49.7 & 65.5 & -16.6 & 17.5 & 29.1 & 27.9 & -1.3 & 4.0 & 28.6 & 36.0 & -9.6 & -7.0 \\
\hline Mean & 36.5 & 38.8 & 5.4 & 0.4 & 38.1 & 37.1 & -5.6 & -0.8 & 32.5 & 41.7 & -7.0 & -6.5 \\
\hline
\end{tabular}

$38^{\circ}$ ) are observed at the western coast near the shoreline. These values could be explained by the fact that model results tend to be less accurate when measured winds come from land (see Table 6). At the most eastern part of the northern coast high values of RMSE are also observed, although they are more dependent on the low wind speed measured all over the northern coast (Figs. $5 a, b)$. Bias distribution shows low values for the entire domain. Along the western coast the highest positive values (about $6^{\circ}$ ) near the shoreline are identified, indicating that QuikSCAT tends to rotate clockwise the wind direction. For the rest of the area, bias values range between $-1^{\circ}$ and $2^{\circ}$.

\section{Conclusions}

The main objective of this work was to assess satellite and modeled data wind patterns accuracy along the Galician coast through a comparative analysis between surface winds obtained from QuikSCAT measurements, WRF Model, and in situ wind. Three control stations were selected following the shoreline orientation, corresponding to the location of three ocean buoys located along the coast. A spatial comparison between satellite and modeled data was also conducted to evaluate their quality around this area. The comparison has been performed from November 2008 to October 2009. From this analysis, the following can be concluded:

- The accuracy of the wind speed derived from the QuikSCAT and the WRF Model was similar all along the coast, showing RMSE errors between 1.5 and $2 \mathrm{~m} \mathrm{~s}^{-1}$. The calculated bias for QuikSCAT data was positive at the three stations $\left(0.5 \mathrm{~m} \mathrm{~s}^{-1}\right)$, while the bias for WRF predictions was positive at the western $\left(0.3 \mathrm{~m} \mathrm{~s}^{-1}\right)$ and middle $\left(0.1 \mathrm{~m} \mathrm{~s}^{-1}\right)$ coast and negative at the northern one $\left(-0.3 \mathrm{~m} \mathrm{~s}^{-1}\right)$.

- Similar RMSE values were found for wind direction at the three stations $\left(35^{\circ}\right)$. Wind direction bias also showed a similar pattern between satellite and modeled data, with positive values at the western coast and negative values at the middle and northern coasts, although always lower in absolute value for WRF data.

- From the analysis carried out considering different wind speed ranges, it was found that QuikSCAT tends to overestimate wind speeds within the whole ranges. RMSE and biases tend to be lower for moderate winds at the three stations for both satellite and modeled data.

- Regarding the direction sectors analysis, the lowest errors and biases were observed at the same sectors for both databases at the three stations (south: Silleiro, west: Villano, and east-west: Bares). The model tends to be less accurate when in situ measured winds come from land.

- From the spatial comparison between satellite and modeled data it was found that the modeled winds tend to be lower than satellite winds over the entire domain, with the highest RMSE and bias values found near the shoreline.

The analyses revealed that the WRF Model and QuikSCAT satellite data are consistent tools to obtain representative wind data near the coast showing good results when compared with in situ wind observations. In addition, because of the nearshore land contamination of satellite values and the lack of anemometers in the coastal region, the model presents clear advantages in the representation of the nearshore wind regime. Thus, the wind model predictions becomes a useful tool to analyze the Galician coast, helping to better understand the wind-induced phenomena, which take place in this region. In fact, the accuracy of the model predictions makes them suitable to perform the precise study of the physical processes driving several coastal phenomena. For example, the study of ocean chlorophyll $a$ concentration distribution and evolution requires the knowledge of accurate wind fields, since it is highly sensitive to changes in wind forcing (Alvarez et al. 2012) and its seasonal variability is mainly related to upwelling events during spring and summer seasons. The study of the dispersal of river plumes also needs the knowledge of precise wind fields, since they respond rapidly to wind 

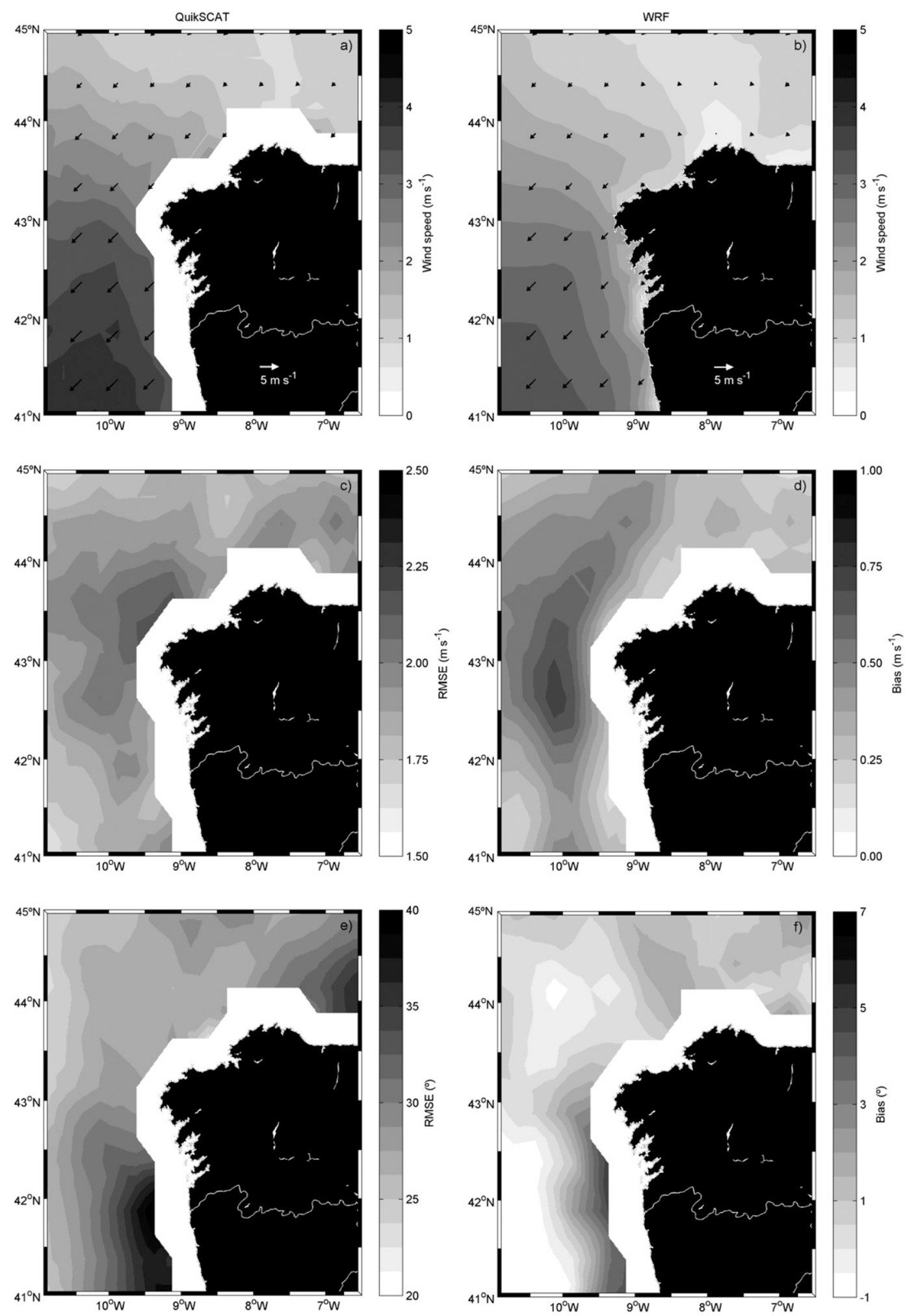

FIG. 5. Mean annual wind circulation obtained from (a) satellite and (b) model along the Galician coast from November 2008 to October 2009. RMSE and bias for (c),(d) wind speed and (e),(f) wind direction from QuikSCAT-WRF data. 
variations, which determine the horizontal freshwater dispersal pattern (Choi and Wilkin 2007; Otero et al. 2008; Vaz et al. 2009). Southerly winds confine the plume to the coast; during the declining phase of the event, the plume expands due to the relaxation of the wind, and extends offshore during the upwelling pulse.

Acknowledgments. The first author of this work has been supported by the Fundação para a Ciência e Tecnologia through a doctoral grant (Grant SFRH/BD/ 60209/2009). The second author acknowledges the support by the Ramon y Cajal program. The third author is supported by the Ciência 2008 program. This research was partially financed by the Ministério de Ciência e Innovación de España (Spain) through the GALINCLIMARCH Project and by Xunta de Galicia under project 10PXIB383169PR, cofinanced by the European Regional Development Fund (FEDER).

\section{REFERENCES}

Accadia, C., S. Zecchetto, A. Lavagnini, and A. Speranza, 2007: Comparison of $10-\mathrm{m}$ wind forecasts from a regional area model and QuikSCAT scatterometter wind observations over the Mediterranean Sea. Mon. Wea. Rev., 135, 1945-1960.

Alvarez, I., M. deCastro, R. Prego, and M. Gomez-Gesteira, 2003: Hydrographic characterization of a winter-upwelling event in the Ria of Pontevedra (NW Spain). Estuarine Coastal Shelf Sci., 56, 869-876.

—, M. Gomez-Gesteira, M. deCastro, and R. Prego, 2005: Variation in upwelling intensity along the NorthWest Iberian Peninsula (Galicia). J. Atmos. Ocean Sci., 10 (4), 309-324.

__ and Coauthors, 2006: Use of MeteoGalicia wind data to monitor oil spills of the Galician coast: Comparison with QuikSCAT data. Cienc. Mar., 32 (2B), 351-360.

—, M. Gomez-Gesteira, M. deCastro, and E. M. Novoa, 2008: Ekman transport along the Galician Coast (NW, Spain) calculated from QuikSCAT winds. J. Mar. Syst., 72, 101-115.

— , and Coauthors, 2009: A winter upwelling event in the Northern Galician Rias: Frequency and oceanographic implications. Estuarine Coastal Shelf Sci., 82, 573-582.

_- M. Gomez-Gesteira, M. deCastro, J. L. Gomez-Gesteira, and J. M. Dias, 2010: Summer upwelling frequency along the western Cantabrian coast from 1967 to 2008. J. Mar. Syst., 79, 218-226.

,,,--- M. N. Lorenzo, A. J. C. Crespo, and J. M. Dias, 2011: Comparative analysis of upwelling influence between the western and northern coast of the Iberian Peninsula. Cont. Shelf Res., 31, 388-399.

_- M. N. Lorenzo, and M. deCastro, 2012: Analysis of chlorophyll $a$ concentration along the Galician coast: Seasonal variability and trends. ICES J. Mar. Sci., 69 (5), 728-738, doi:10.1093/icesjms/fss045.

Bentamy, A., H. L. Ayina, P. Queffeulou, D. Croize-Fillon, and V. Kerbaol, 2007: Improved near real time surface wind resolution over the Mediterranean Sea. Ocean Sci., 3, 259-271.

Bode, A., M. Varela, B. Casas, and N. Gonzalez, 2002: Intrusions of eastern North Atlantic central waters and phytoplankton in the north and northwestern Iberian shelf during spring. J. Mar. Syst., 36, 197-218.
Borja, A., A. Uriarte, V. Valencia, L. Motos, and A. Uriarte, 1996: Relationships between anchovy (Engraulis encrasicholus) recruitment and the environment in the Bay of Biscay. Sci. Mar., 60, 179-192.

Chelton, D. B., and M. H. Freilich, 2005: Scatterometter-based assessment of $10-\mathrm{m}$ wind analyses from the operational ECMWF and NCEP numerical weather prediction models. Mon. Wea. Rev., 133, 409-429.

Choi, B., and J. L. Wilkin, 2007: The effect of wind on the dispersal of the Hudson River plume. J. Phys. Oceanogr., 37, 1878-1897.

deCastro, M., N. Lorenzo, J. J. Taboada, M. Sarmiento, I. Alvarez, and M. Gómez-Gesteira, 2006: Influence of teleconnection patterns on precipitation variability and on river flow regimes in the Miño River basin (NW Iberian Peninsula). Climate Res., 32, 63-73.

— M. Gómez-Gesteira, M. N. Lorenzo, I. Alvarez, and A. J. C. Crespo, 2008: Influence of atmospheric modes on coastal upwelling along the western coast of the Iberian Peninsula, 1985 to 2005. Climate Res., 36, 169-179.

Ebuchi, N., H. C. Graber, and M. J. Caruso, 2002: Evaluation of wind vectors observed by QuikSCAT/SeaWinds using ocean buoy data. J. Atmos. Oceanic Technol., 19, 2049-2062.

Fraga, F., 1981: Upwelling off the Galician Coast, Northwest Spain. Coastal Upwelling, F. A. Richardson, Ed., Amer. Geophys. Union, 176-182.

Gomez-Gesteira, M., C. Moreira, I. Alvarez, and M. deCastro, 2006: Ekman transport along the Galician coast (NW, Spain) calculated from forecasted winds. J. Geophys. Res., 111, C10005, doi:10.1029/2005JC003331.

Johnson, H. K., 1999: Simple expressions for correcting wind speed data for elevation. Coastal Eng., 36, 262-269.

Jet Propulsion Laboratory, cited 2001: Seawinds on QuikSCAT level 3 daily gridded ocean winds vectors (JPL version 2). JPL Seawinds Project, Jet Propulsion Laboratory. [Available online at http://podaac.jpl.nasa.gov/dataset/QSCAT_LEVEL_3_V2.]

Large, W. G., and S. Pond, 1981: Open ocean momentum flux measurements in moderate to strong winds. J. Phys. Res., 11, 324-336.

_ J. Morzel, and G. B. Crawford, 1995: Accounting for surface wave distortion of the marine wind profile in low-level ocean storms wind measurements. J. Phys. Oceanogr., 25, 2559-2971.

Liu, W. T., and W. Tang, 1996: Equivalent neutral winds. Jet Propulsion Laboratory Publ., Pasadena, CA, 16 pp.

_ zation of air-sea exchanges of heat and water vapor including the molecular constraints at the interface. J. Atmos. Sci., 36, 1722-1735.

Milliff, R. F., J. Morzel, D. B. Chelton, and M. H. Freilich, 2004: Wind stress curl and wind divergence biases from rain effects on QSCAT surface wind retrievals. J. Atmos. Oceanic Technol., 21, 1216-1231.

Ospina-Alvarez, N., and Coauthors, 2010: Oceanographical patterns during a summer upwelling-downwelling event in the Northern Galician Rias: Comparison with the whole Ria system (NW of Iberian Peninsula). Cont. Shelf Res., 30, 1362-1372.

Otero, P., and M. Ruiz-Vilarreal, 2008: Wind forcing of the coastal circulation off north and northwest Iberia: Comparison of atmospheric models. J. Geophys. Res., 113, C10019, doi:10.1029/2008JC004740.

$\ldots,-$, and A. Peliz, 2008: Variability of river plumes off Northwest Iberia in response to wind events. J. Mar. Syst., 72, 238-255. 
Penabad, E., I. Alvarez, C. F. Balseiro, M. deCastro, B. Gómez, V. Pérez-Muñuzuri, and M. Gómez-Gesteira, 2008: Comparative analysis between operational weather prediction models and QuikSCAT wind data near the Galician coast. J. Mar. Syst., 72, 256-270.

Pensieri, S., R. Bozzano, and M. E. Schiano, 2010: Comparison between QuikSCAT and buoy wind data in the Ligurian Sea. J. Mar. Syst., 81, 286-296.

Pickett, M. H., W. Tang, L. K. Rosenfeld, and C. H. Wash, 2003: QuikSCAT satellite comparisons with nearshore buoy wind data off the U.S. west coast. J. Atmos. Oceanic Technol., 20, 1869-1879.

Portabella, M., and A. Stoffelen, 2001: Rain detection and quality control of SeaWinds. J. Atmos. Oceanic Technol., 18,1171-1183.

Prego, R., D. Guzmán-Zuñiga, M. Varela, M. deCastro, and M. Gomez-Gesteira, 2007: Consequences of winter upwelling events on biogeochemical and phytoplankton patterns in a western Galician Ria (NW Iberian Peninsula). Estuarine Coastal Shelf Sci., 73, 409-422.

Ruti, P. M., S. Marullo, F. D'Ortensio, and M. Tremant, 2008: Comparison of analyzed and measured wind speeds in the perspective of oceanic simulations over the Mediterranean basin: Analyses, QuikSCAT, and buoy data. J. Mar. Sci., 70, 33-48.

Santos, A. M. P., A. Peliz, J. Dubert, P. B. Oliveira, M. M. Angelico, and P. Re, 2004: Impact of a winter upwelling event on the distribution and transport of sardine (Sardina pilchardus) eggs and larvae off western Iberia: A retention mechanism. Cont. Shelf Res., 24, 149-165.

Satheesan, K., A. Sarkar, A. Parekh, M. R. Ramesh Kumar, and Y. Kuroda, 2007: Comparison of wind data from QuikSCAT and buoys in the Indian Ocean. Int. J. Remote Sens., 10, $2375-2382$.

Skamarock, W. C., and Coauthors, 2008: A description of the Advanced Research WRF version 3. NCAR Tech. Note NCAR/TN-475+STR, 113 pp.

Stiles, B. W., and S. H. Yeuh, 2002: Impact of rain on spaceborne Ku-band wind scattermeter data. IEEE Trans. Geosci. Remote Sens., 40, 1973-1983.

Tang, W., W. T. Liu, and B. W. Stiles, 2004: Evaluation of highresolution ocean surface vector winds measured by QuikSCAT scatterometer in coastal regions. IEEE Trans. Geosci. Remote Sens., 42, 1762-1769.

Torres, R., E. D. Barton, P. Miller, and E. Fanjul, 2003: Spatial patterns of wind and sea surface temperature in the Galician upwelling region. J. Geophys. Res., 108, 3130, doi:10.1029/ 2002JC001361.

Varela, M., R. Prego, and Y. Pazos, 2008: Spatial and temporal variability of phytoplankton biomass, primary production and community structure in the Pontevedra Ria (NW Iberian Peninsula): Oceanographic periods and possible response to environmental changes. Mar. Biol., 154, 483-499.

- M. Alvarez-Ossorio, A. Bode, R. Prego, P. Bernardez, and C. Garcia-Soto, 2010: The effects of a winter upwelling on biogeochemical and planktonic components in an area close to the Galician upwelling core: The Sound of Corcubion (NW Spain). J. Sea Res., 64, 260-272.

Vaz, N., L. Fernandes, P. C. Leitão, J. M. Dias, and R. Neves, 2009: The Tagus estuarine plume induced by wind and river runoff: Winter 2007 case study. J. Coastal Res., SI56, 10901094. 